\title{
Transmural, haemorrhagic myocardial infarction after intracoronary streptokinase Clinical, angiographic, and necropsy findings
}

\author{
DETLEF G MATHEY, JOACHIM SCHOFER, KARL-HEINZ KUCK, \\ ULRICH BEIL, GÜNTER KLÖPPEL
}

From the Departments of Cardiology, Medicine, and Pathology, University Hospital Eppendorf, Hamburg, West Germany

SUMMARY Six of 101 patients with acute myocardial infarction whose coronary arteries were successfully recanalised died in cardiogenic shock one to 18 days after intracoronary thrombolysis. In one patient, cardiogenic shock was preceded by coronary artery reocclusion. On admission, serum creatine kinase was still normal in all six patients and there was significant ST elevation but no changes in the QRS complexes. Four of the six patients had an old infarct. The time between the onset of symptoms and coronary artery recanalisation was approximately 2.9 hours. The total dosage of intracoronary streptokinase averaged 200000 units. Necropsy disclosed a patent vessel supplying the infarct in five patients and thrombotic reocclusion in the one patient with reinfarction. All six patients had a transmural acute myocardial infarction, which was typically anaemic in the two patients with inferior infarction. In one of these two patients, whose artery was recanalised within 1.7 hours, the anaemic infarct was only $4 \mathrm{~cm}^{2}$ in area, whereas in the other (the patient who died after reocclusion) it was $30 \mathrm{~cm}^{2}$. In three patients with an acute occlusion of the left anterior descending coronary artery, whose vessels were recanalised within 3.5 hours, the infarct was haemorrhagic and large, averaging 32 $\mathrm{cm}^{2}$. Haemorrhage was always confined to the area of necrosis and there was no evidence of cardiac rupture. One other patient had both types of infarction-a large haemorrhagic infarct in the area of the recanalised circumflex coronary artery and an anaemic infarct in the area supplied by the severely stenosed left anterior descending coronary artery.

In this patient, who died 18 days after recanalisation, the speed of infarct healing was much delayed in the haemorrhagic but not in the anaemic infarct area.

Despite coronary artery recanalisation within three and a half hours, a fatal transmural acute myocardial infarction with reperfusion haemorrhage into the area of necrosis may occur. Myocardial haemorrhage probably delays infarct healing.

During the past three years, we have successfully recanalised the coronary arteries of 101 patients with an acute transmural myocardial infarction using intracoronary streptokinase. Six of the 101 patients died in cardiogenic shock one to 18 days after the procedure. Death was preceded by reinfarction caused by coronary artery reocclusion in only one patient. In all six patients, necropsy was performed in order to assess infarct size objectively and to differentiate an anaemic from a haemorrhagic infarct. Experimentally, haemorrhagic infarction has been observed after myocardial reperfusion, and from systemic strepto-

Accepted for publication 9 August 1982 kinase treatment it is known that myocardial haemorrhage also occurs in man. ${ }^{1}$ In this paper, the necropsy findings of the six patients are summarised and related to clinical and angiographic data.

\section{Methods}

CLINICAL CHARACTERISTICS ON ADMISSION According to our procedure, the duration of chest pain was less than three hours in all six patients. One patient was already in the hospital when the infarct occurred another was working at the hospital when his chest pain began. On admission, all six patients were in left ventricular failure. Arterial blood pressure, however, 
was still within the normal range. Four patients had a history of an old transmural myocardial infarction. The electrocardiogram showed distinct ST elevation, with no evidence of new $Q$ waves. Serum creatine kinase was within normal limits, confirming the early stage of the infarct.

RECANALISATION AND

POST - THROMBOLYTIC TREATMENT

Coronary artery recanalisation was performed as described by us previously. ${ }^{2}$ First, the "infarct vessel" was recanalised, then the non-affected coronary artery and the left ventricle were visualised. In one patient, streptokinase was given superselectively through a 3 French reperfusion catheter, which was advanced through an 8 French Judkins right coronary artery catheter up to the thrombus. In another patient, where streptokinase had transformed a total into a subtotal occlusion, intracoronary lysis was followed by balloon dilatation using a Grüntzig dilatation catheter DG 2030.

Five of the six patients were still in the intensive care unit when they died. The patient with reinfarction was in the general ward and was readmitted to the intensive care unit; she died two days later. All patients received intravenous heparin and, as long as their blood pressure permitted, they also received intravenous glyceryl trinitrate ( $50 \mathrm{mg}$ daily) and oral nifedipine (20 mg four times daily), in order to prevent coronary artery reocclusion from spasm. Haemodynamic variables were monitored with a Swan-Ganz catheter and medical treatment was administered according to these measurements. When left ventricular failure worsened, the patients were intubated and artificially ventilated.

\section{NECROPS Y}

The necropsies were performed 24 to 30 hours after death. The hearts were weighed and examined according to a routine procedure. First, the coronary arteries were carefully prepared and dissected, in order to identify the exact location and extent of the atheroma- tous stenoses and thromboses. Second, the chambers were opened and the degree of dilatation was measured and recorded, together with other qualitative changes, such as subendocardial bleeding or parietal thrombosis. Third, horizontal sections were cut through the anterior wall of the left ventricle as well as the interventricular septum and the inferior left ventricular wall. On these cut surfaces the size and the quality of the infarct were assessed. For histological evaluation, two or three specimens were taken from the centre of the infarct, from the margin, and from the noninfarcted myocardium.

\section{Results}

\section{ANGIOGRAPHIC FINDINGS}

Coronary angiography disclosed three vessel disease in all six patients. The "infarct vessel" was completely occluded. It was recanalised by a streptokinase infusion into the ostium of the right or left coronary artery in four patients, a superselective streptokinase infusion in one patient, and a streptokinase infusion followed by balloon dilatation in the remaining patient. The average streptokinase dosage was $200000 \pm 25000$ units. The time interval from the onset of chest pain to recanalisation was $2.9 \pm 0.8$ hours, ranging from 1.7 to 3.5 hours (Table). A significant arteriosclerotic stenosis always remained after recanalisation, but there was good and prompt contrast filling of the previously occluded artery. Angiographically, there was no evidence of preformed collaterals to the "infarct vessel" in any of the six patients. The left ventricular ejection fraction immediately after recanalisation was conspicuously reduced to $26 \pm 8 \%$.

CLINICAL COURSE AFTER RECANALISATION In case 1 , recanalisation was associated with distinct clinical improvement and the reversal of impending shock. Nine days after recanalisation, however, reinfarction occurred as evidenced by typical ischaemic chest pain, ST re-elevation, and a rise in serum creatine kinase. A second attempt to recanalise the reoccluded

Table Summary of clinical, angiographic, and necropsy data

\begin{tabular}{|c|c|c|c|c|c|c|c|c|c|c|c|c|}
\hline $\begin{array}{l}\text { Case } \\
\text { No. }\end{array}$ & Sex & $\begin{array}{l}\text { Age } \\
(y)\end{array}$ & $A M I$ & $\begin{array}{l}\text { Old } \\
M I\end{array}$ & $\begin{array}{l}\text { Infarct } \\
\text { vessel }\end{array}$ & $\begin{array}{l}\text { Intracoronary } \\
\text { streptokinase } \\
\text { (units) }\end{array}$ & $\begin{array}{l}\text { Chest pain } \\
\text { to reperfusion } \\
\text { (hours) }\end{array}$ & $\begin{array}{l}\text { Peak serum } \\
C K(U / l)\end{array}$ & $\begin{array}{l}\text { AMI to } \\
\text { death } \\
\text { (d) }\end{array}$ & $\begin{array}{l}\text { Coronary artery } \\
\text { reocclusion }\end{array}$ & $\begin{array}{l}A M I \text { area } \\
\left(\mathrm{cm}^{2}\right)\end{array}$ & $\begin{array}{l}\text { Myocardial } \\
\text { haemorrhage }\end{array}$ \\
\hline $\begin{array}{l}1 \\
2 \\
3 \\
4 \\
5 \\
6\end{array}$ & $\begin{array}{l}F \\
M \\
M \\
F \\
M \\
M\end{array}$ & $\begin{array}{l}71 \\
70 \\
69 \\
77 \\
72 \\
44\end{array}$ & $\begin{array}{l}\mathbf{I} \\
\mathbf{I} \\
\mathbf{A} \\
\mathbf{A} \\
\mathbf{A} \\
\mathrm{I}(+\mathbf{A})\end{array}$ & $\begin{array}{l}\text { A } \\
\text { A } \\
\text { I } \\
\text { I } \\
-\end{array}$ & $\begin{array}{l}\text { RCA } \\
\text { RCA } \\
\text { LAD } \\
\text { LAD } \\
\text { LAD } \\
\text { Cfx } \\
(+ \text { LAD) }\end{array}$ & $\begin{array}{l}175000 \\
200000 \\
190000 \\
190000 \\
250000 \\
200000\end{array}$ & $\begin{array}{l}2.0 \\
1.7 \\
3.5 \\
3.4 \\
3.5 \\
3.0\end{array}$ & $\begin{array}{r}428 \\
250 \\
1968 \\
3350 \\
4000 \\
3100\end{array}$ & $\begin{array}{r}9 \\
2 \\
1 \\
3 \\
1 \\
18\end{array}$ & $\begin{array}{l}+ \\
- \\
- \\
- \\
- \\
-\end{array}$ & $\begin{array}{r}30 \\
4 \\
30 \\
24 \\
42 \\
99\end{array}$ & $\begin{array}{l}- \\
- \\
+ \\
+ \\
+ \\
+(-)\end{array}$ \\
\hline
\end{tabular}

AMI, acute myocardial infarction; MI myocardial infarction; I, inferior; A, anterior; RCA, right coronary artery; LAD, left anterior descending coronary artery; Cfx, circumflex coronary artery. 
proximal right coronary artery with streptokinase was unsuccessful and the patient died in cardiogenic shock.

In cases 2 to 6 , left ventricular failure persisted after recanalisation. These five patients required increasing dosages of positive inotropic agents to maintain their arterial pressure. There was no evidence of reinfarction before death in these five patients. They all died in cardiogenic shock.

Serum creatine kinase rose rapidly after recanalisation. Peak serum creatine kinase in cases 1 and 2 was 428 and 250 units/l, respectively, and in cases 3 to 6 peak creatine kinase averaged $3104 \pm 847$ units/l (Table). New $Q$ waves appeared in all six patients after recanalisation.

NECROPSY FINDINGS WITH RESPECT

TO RECANALISATION

Necropsy disclosed a patent "infarct vessel" in cases 2 to 6 and an acute thrombotic reocclusion in case 1 with reinfarction. At the sites where thrombotic occlusions had been detected by angiography before recanalisation, the coronary arteries showed severe arteriosclerotic stenoses.

All six patients had a transmural infarct (Table). In cases 1 and 2, with inferior infarctions, the infarct was typically anaemic; their sizes were $30 \mathrm{~cm}^{2}$ and $4 \mathrm{~cm}^{2}$, respectively. Both patients had an old anterior infarct and in both recanalisation was achieved in less than two hours after the onset of chest pain. There was discrete involvement of the right ventricle in case 1 .

In cases 3 to 5 , with acute occlusion of the left anterior descending coronary arteries, the "infarct vessel" was opened within three and a half hours after the onset of chest pain. Necropsy showed large transmural infarcts averaging $32 \pm 9 \mathrm{~cm}^{2}$ in area. The infarcts were almost completely haemorrhagic, leaving only a small anaemic border zone. Haemorrhage was always confined to the area of necrosis with no evidence of cardiac rupture. A typical example is shown in Fig. 1. Histologically, the haemorrhagic infarct was characterised by eosinophilic coagulation necrosis of the myocardial fibres. This was accompanied by intensive fresh haemorrhage between the myofibres (Fig. 2a). A neutrophilic exudation was almost absent. The wall of the small arterial vessels also appeared to be necrotic (Fig. 2b).

Case 6, who died 18 days after recanalisation, had a haemorrhagic infarct in the area supplied by the occluded and recanalised circumflex coronary artery and an anaemic infarct in the area supplied by the severely stenosed left anterior descending coronary artery (Fig. 3). Streptokinase had been infused into the left main coronary artery in this patient. According to the single peak in serum creatine kinase and the infarct age estimated on the basis of the gross and microscopical changes, the anterior anaemic infarct probably

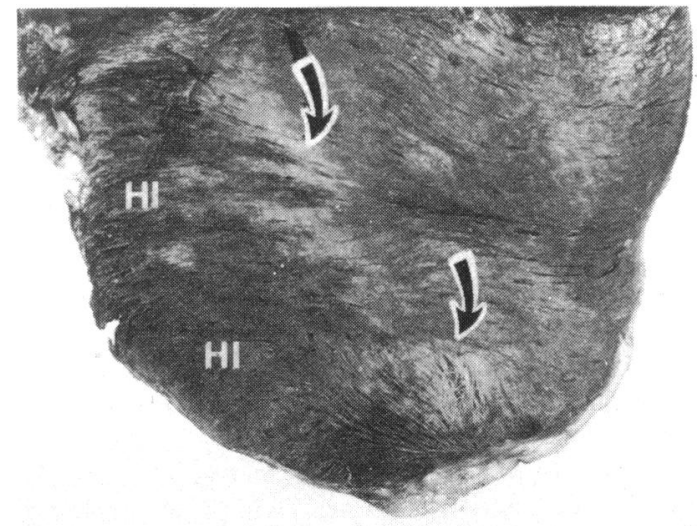

Fig. 1 Horizontal cut surface of the septum and the posterior wall of the left ventricle with acute haemorrhagic infarct $(H I)$ affecting almost the entire interventricular septum (case 5). Anaemic margin (arrows).

occurred at the same time as the posterolateral haemorrhagic infarct. Since this patient died 18 days after recanalisation, histological samples from the anaemic and haemorrhagic infarct areas were examined with special regard to the question whether the speed of infarct healing was affected by myocardial haemorrhage. Fig. 4 shows a specimen from the margin of the anaemic infarct directly adjacent to the haemorrhagic infarct. The area of the anaemic infarct shows signs of advanced repair with granulation tissue almost completely replacing the necrotic muscle fibres. In contrast, the area of the haemorrhagic infarct showed no signs of repair.

\section{Discussion}

The clinicopathological observations described in this paper are the first obtained in patients who have had intracoronary streptokinase treatment. It is the nature of such data that they are "negative" and selective.

Clinically and angiographically, our six patients did not recognisably differ from many other patients undergoing coronary artery recanalisation, with the exception that their left ventricular ejection fraction was so depressed. All six patients had recanalisation within the time limit at present considered to be appropriate for patients with acute myocardial infarction. ${ }^{2-4}$ The normal serum creatine kinase levels on admission and the acute electrocardiographic findings make it unlikely that the onset of coronary artery occlusion was significantly different from the onset of chest pain in these patients.

In cases 1 and 2, coronary artery reperfusion was achieved within two hours after the onset of chest pain. It may have salvaged ischaemic myocardium in case 2 , 


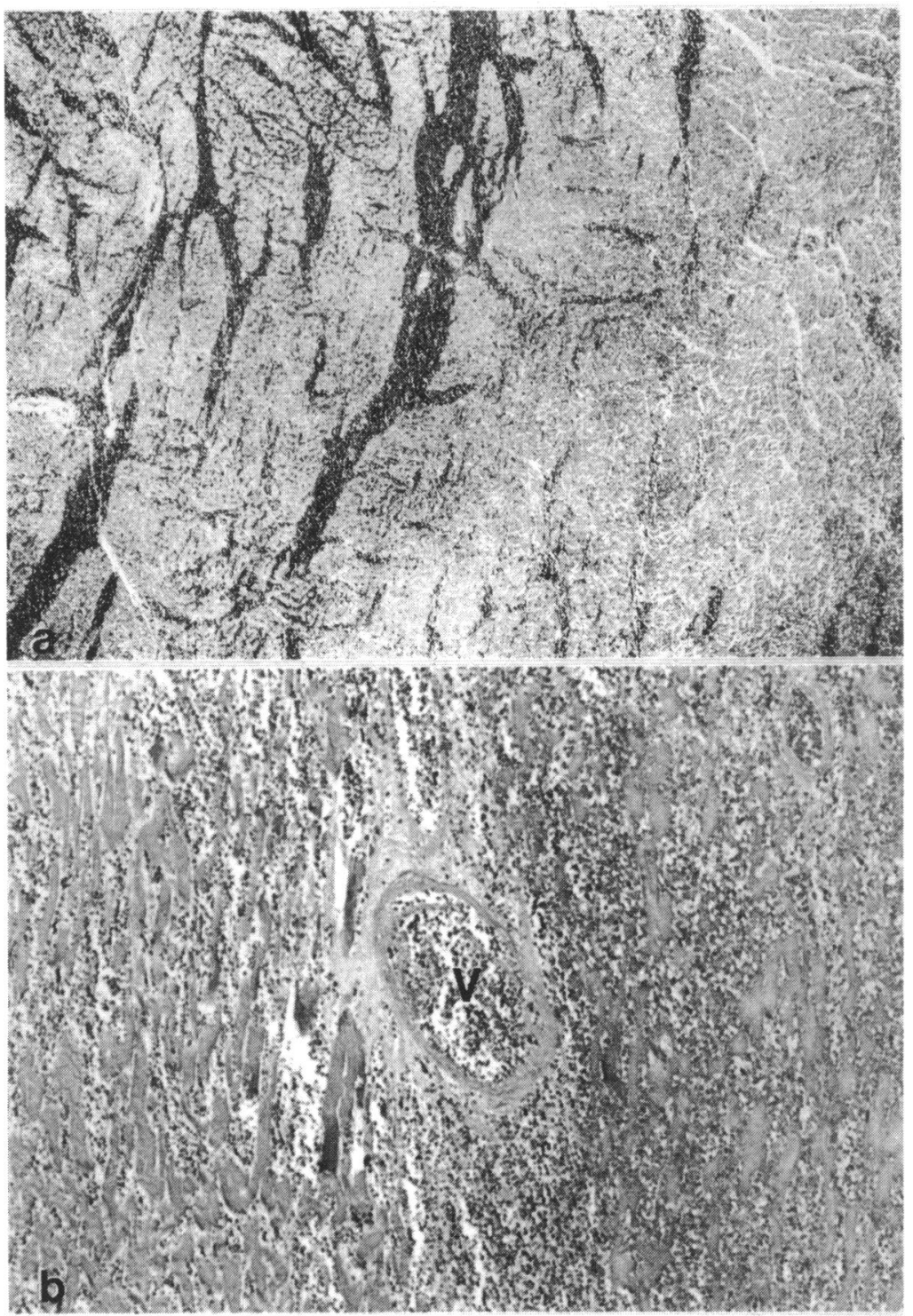

Fig. 2 Acute haemorrhagic infarction. (a) Low power micrograph showing interconnecting strands of erythrocytes between myofibres. ( $H E \times 40$, original magnification.) (b) High power micrograph displaying massive haemorrhage between necrotic myofibres. In the centre a small vessel (V) with necrotic wall. ( $H E \times 115$, original magnification.)

since only a small, anaemic infarct was found at necropsy.

This patient probably died from the overall amount of dysfunctioning myocardium, that is the old anterior infarct, the acute inferior infarct, and the reperfused myocardium still recovering from ischaemia. In case 1 , the beneficial effects of recanalisation were apparent only initially; the symptoms of impending cardiogenic shock disappeared. Reocclusion, however, resulted in reinfarction and irreversible shock. Thus, the beneficial effect of coronary artery recanalisation could not be sustained in this patient. In cases 3 to 6 , the clinical course and the necropsy findings indicate that recanalisation achieved within three and a half hours after the onset of chest pain did not prevent a fatal extensive myocardial infarction. Apparently, recanalisation was too late to salvage myocardium in these patients. In addition, there is little doubt that recanalisation produced a haemorrhagic type of myocardial infarction.

A haemorrhagic myocardial infarction is rarely seen. Reviewing our last 200 necropsies of patients who died after an acute myocardial infarction, no haemorrhagic infarct was found even in five patients who received intracoronary streptokinase but in whom the "infarct vessel" was not reopened. Myocardial haemorrhage 


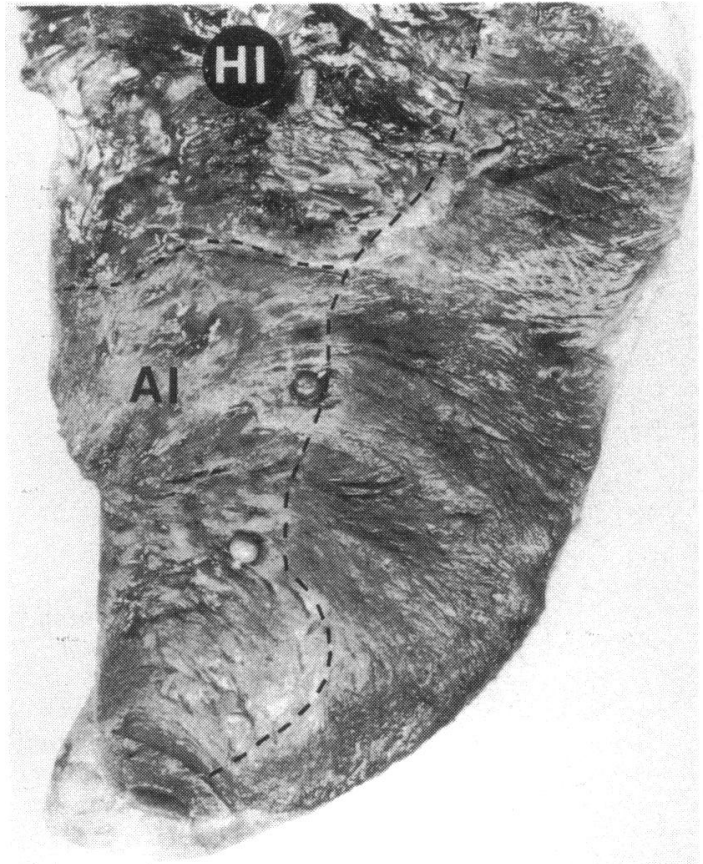

Fig. 3 Horizontal cut surface of the anterior wall of the left ventricle with an 18 day old haemorrhagic infarct $(H I)$ at the basis (case 6). Close by, an anaemic infarct (AI) of equal age.

has been described after systematic streptokinase. Since it is also observed after experimental reperfusion and occasionally after coronary artery bypass in patients with acute myocardial infarction, ${ }^{5}$ however, it may not be the result of streptokinase per se, but the consequence of early myocardial reperfusion after intracoronary thrombolysis. The findings in our last patient (case 6) would be consistent with this hypothesis. This patient had a haemorrhagic and an anaemic infarct of equal age. The haemorrhagic infarct occurred only in the area of the totally occluded and recanalised coronary artery, whereas the anaemic infarct occurred in the area of the severely stenosed left anterior descending coronary artery, where no reperfusion took place. Thus, sudden reperfusion after three to four hours of coronary artery occlusion appears to be a major determinant in the development of myocardial haemorrhage. The anaemic anterior infarct in this patient may have been caused by a drop in perfusion pressure and/or loss in collateral blood flow from the acutely occluded circumflex coronary artery to the left anterior descending coronary artery. Since this patient died 18 days after recanalisation and had both types of infarction, it was interesting to see how the speed of healing of the acute infarct was affected by myocardial haemorrhage. The histological specimens from this patient showed a clear-

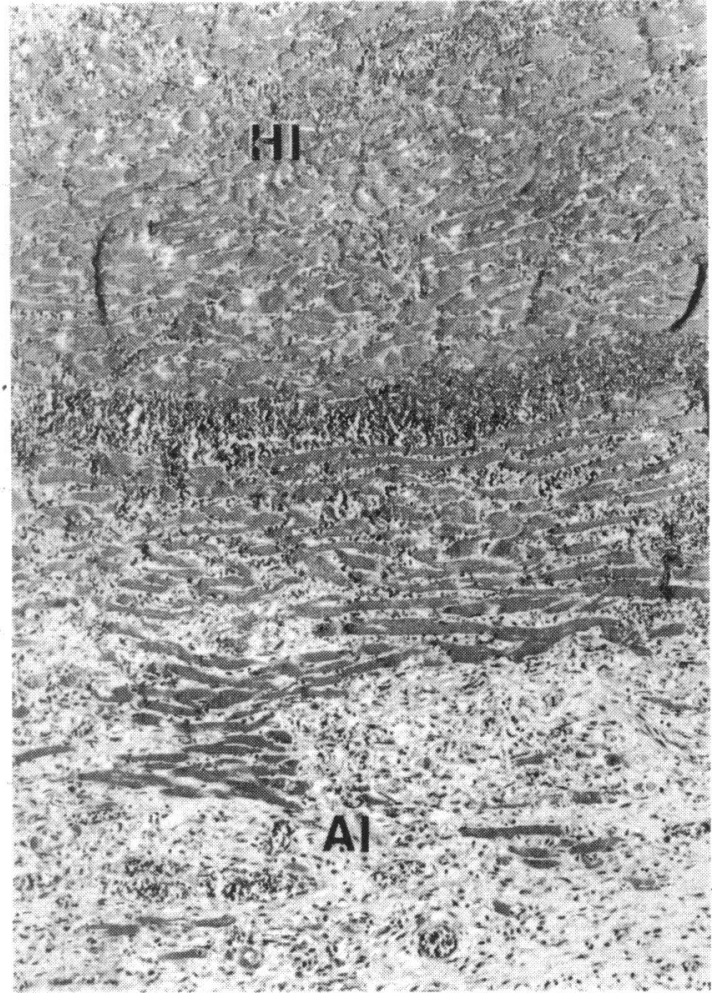

Fig. 4 Anaemic infarct ( $A I)$ in repair (case 6), characterised by granulation tissue, adjacent to a haemorrhagic infarct $(H I)$ of the same age without any evidence of repair. ( $H E \times 115$, original magnification.)

cut difference in the removal of necrotic muscle and replacement by connective tissue between the anaemic and the haemorrhagic infarct. While in the haemorrhagic infarct area, repair processes were completely lacking after 18 days, the anaemic infarct showed the typical picture of an infarct in resorption and repair by granulation tissue. Obviously, myocardial haemorrhage delayed infarct healing in this patient. In case 4, who died three days after an acute anterior infarct, the expected degree of leucocytic infiltration was also not seen.

Thus, our findings show that a large fatal infarct may occur despite recanalisation within three and a half hours after the onset of chest pain. They also suggest that myocardial haemorrhage is likely to follow coronary artery reperfusion, thereby possibly delaying the speed of infarct healing.

Although we cannot be certain that a haemorrhagic infarct similar to that in cases 3 to 6 is not present in many patients undergoing recanalisation and surviving the acute infarct, we have continued to undertake this procedure. A substantial improvement in regional wall 
motion after successful thrombolysis ${ }^{6}$ in connection with a reduction in thallium-201 defect size in the majority of patients, as well as distinct haemodynamic improvement in some patients with cardiogenic shock ${ }^{7}$ has encouraged us. We attempt, however, to recanalise patients with an extensive anterior infarct as early as possible with a strict limit on the acceptable duration of symptoms of three hours. Otherwise, instead of a reduction in infarct size, myocardial haemorrhage is likely to be induced, thereby possibly disturbing infarct healing. We are aware that a large interindividual variation in the development of a complete myocardial infarction exists.

\section{References}

1 Schachenmayr W, Haferkamp O. Der hämorrhagische Herzinfarkt. Dtsch Med Wochenschr 1972; 97: 1172-4.

2 Mathey DG, Kuck, KH, Tilsner V, Krebber HJ, Bleifeld W. Nonsurgical coronary artery recanalization in acute transmural myocardial infarction. Circulation 1981; 63: 489-97.

3 Ganz W, Buchbinder N, Marcus H, et al. Intracoronary thrombolysis in evolving myocardial infarction. Am Heart $\mathcal{F}$ 1981; 101: 4-13.

4 Rentrop P, Blanke H, Karsch KR, Kaiser H, Köstering H, Leitz K. Selective intracoronary thrombolysis in acute myocardial infarction and unstable angina pectoris. Circulation 1981; 63: 307-17.

5 Lie JT, Lawrie GM, Morris GC Jr, Winters WL. Hemorrhagic myocardial infarction associated with aortocoronary bypass revascularization. Am. Heart $\mathcal{F}$ 1978; 96: 295-302.

6 Mathey DG, Rodewald G, Rentrop P, et al. Intracoronary streptokinose thrombolytic recanalization and subsequent surgical bypass of remaining atherosclerotic stenosis in acute myocardial infarction: complementary combined approach effecting reduced infarct size, preventing reinfarction, and improving left ventricular function. $\mathrm{Am}$ Heart f 1981; 102: 1194-1201.

7 Mathey DG, Kuck KH, Remmecke J, Tilsner V, Bleifeld W. Transluminal recanalization of coronary artery thrombosis: a preliminary report of its application in cardiogenic shock. Eur Heart $\mathcal{F}$ 1980; 1: 207-12.

Requests for reprints to Professor D G Mathey, Department of Cardiology, University Hospital Eppendorf, Martinistrasse 52, 2000 Hamburg 20, West Germany. 